\title{
Development of an Integrated Cooling System Controller for Hybrid Electric Vehicles
}

\author{
Chong Wang, ${ }^{1}$ Qun Sun, ${ }^{1}$ and Limin $\mathrm{Xu}^{2}$ \\ ${ }^{1}$ School of Mechanical and Automotive Engineering, Liaocheng University, Liaocheng, China \\ ${ }^{2}$ School of International Education, Liaocheng University, Liaocheng, China \\ Correspondence should be addressed to Chong Wang; cwang1@126.com
}

Received 14 January 2017; Accepted 15 March 2017; Published 10 April 2017

Academic Editor: Ephraim Suhir

Copyright (c) 2017 Chong Wang et al. This is an open access article distributed under the Creative Commons Attribution License, which permits unrestricted use, distribution, and reproduction in any medium, provided the original work is properly cited.

\begin{abstract}
A hybrid electrical bus employs both a turbo diesel engine and an electric motor to drive the vehicle in different speed-torque scenarios. The cooling system for such a vehicle is particularly power costing because it needs to dissipate heat from not only the engine, but also the intercooler and the motor. An electronic control unit (ECU) has been designed with a single chip computer, temperature sensors, DC motor drive circuit, and optimized control algorithm to manage the speeds of several fans for efficient cooling using a nonlinear fan speed adjustment strategy. Experiments suggested that the continuous operating performance of the ECU is robust and capable of saving $15 \%$ of the total electricity comparing with ordinary fan speed control method.
\end{abstract}

\section{Introduction}

A hybrid electrical vehicle (HEV) employs both a turbo diesel engine and an electric motor to drive the vehicle in different speed-torque scenarios. An effective thermomanagement system is required to dissipate excessive heat from the engine, intercooler, and the motor to avoid part damage during continuous operations [1]. On buses or coaches the power systems are often mounted in the rear of the vehicles and the radiators are often mounted on one side of the vehicles and cooled by lateral wind pulled in by electrical fans, which consume a large amount of electricity.

Studies on HEV thermomanagement system have been extensive but widely spread in different areas, such as whole vehicle thermomanagement [2-5], pumps and thermostats adjustment [6,7], and battery thermomanagement issues. Within vehicle thermomanagement strategies, cooling fan speed adjustment is a specific topic and often relates to analysis of radiator, flow, and the air. A recent comprehensive study [2] has already addressed several analytical models although it has not led to final controller prototype.

Till now, many vehicles such as Volkswagen Passat B5 still use two-state on-off cooling fan control method, Volkswagen Polo is able to switch cooling fan between high speed and low speed, and Audi A6 adjust fan speed in a linear manner according to water temperature. Some recent studies paid more attention to the nonlinear engine and radiator thermocharacteristics and the corresponding nonlinear PWM control techniques [6-9], which so far has not yielded mass produced equipment.

For large HEV buses or coaches the power consumption of the cooling fans is significant, which requires more advanced cooling control ECU to perform energy saving and vehicle thermomanagement.

\section{The Control System Scheme and Cooling Theories}

This study is focused on fan drive and control unit for efficient cooling of the engine, intercooler, and the motor. The system concept can be described in Figure 1. Large diameter fans up to $385 \mathrm{~mm}$ and $300 \mathrm{w}$ are mounted over the radiators, intercooler, and the motor. Temperature sensors are attached to these parts to measure temperatures and send signals to the controller ECU. The ECU calculates proper control strategies and the duty cycles of PMW outputs and then drives the fans to the proper speeds. Eventually the system controls the water tank outlet temperature below $85^{\circ} \mathrm{C}$, the intercooler temperature below $40^{\circ} \mathrm{C}$, and the motor temperature below $70^{\circ} \mathrm{C}$. 


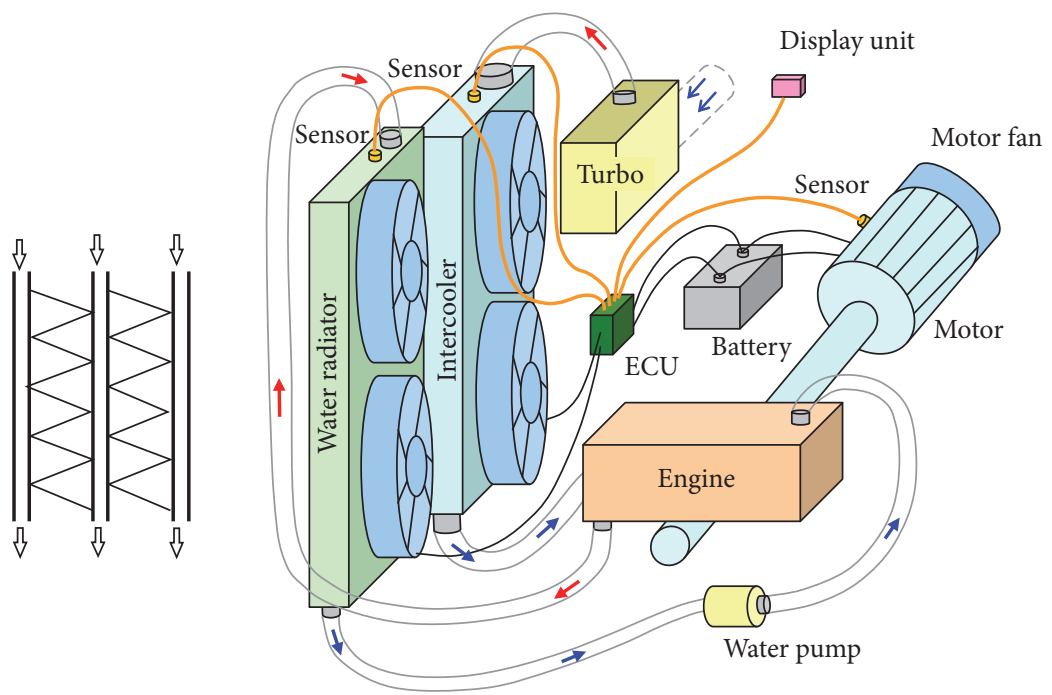

FIGURE 1: The radiator structure and the cooling control system scheme.

According to literatures [10-12], the heat exchanges through a ribbon-tubular radiator can be calculated as the following. The heat transfer area between the coolant and the metal parts of the radiator is

$$
F_{w}=2 \cdot\left(L_{1}+W_{1}\right) \cdot H_{1} \cdot N_{1}
$$

where $L_{1}$ and $W_{1}$ are the length and width of the pipe crosssection, $H_{1}$ is the length of the pipes, and $N_{1}$ is the number of pipes. The thermoarea between the metal parts and the air can be expressed as

$$
F_{A}=2 \cdot\left(2 \cdot \sqrt{H H^{2}+\frac{w^{2}}{4}}+w\right) \cdot H_{1} \cdot \frac{L L}{w} \cdot N_{2},
$$

where $H H$ is wave height and wave distance of the fins, $L L$ is the core thickness, and $N_{2}$ is the number of air side heat exchange channels. Another parameter, logarithmic mean temperature deviation, is used to describe the mean temperature difference of two flows during a thermotransformation process of a radiator $[13,14]$.

$$
\Delta t_{m}=\psi \cdot \frac{\left(t_{h 1}-t_{c 2}\right)-\left(t_{h 2}-t_{c 1}\right)}{\ln \left(\left(t_{h 1}-t_{c 2}\right) /\left(t_{h 2}-t_{c 1}\right)\right)}
$$

where $t_{h 1}$ and $t_{h 2}$ are the temperatures of hot flow at the inlet and outlet, $t_{c 1}$ and $t_{c 2}$ are the temperatures of cold flow at the inlet and outlet, respectively, and $\psi$ is a correction factor ranging from 0.95 to 0.98 according to literature [12]. The amount of thermal exchanges through the radiator can be separately calculated on the first heat dissipation surface around the pipes and the second heat dissipation surface around the fins, as below

$$
\begin{aligned}
& Q_{1}=h_{1} \cdot F_{1} \cdot\left(t_{w}-t_{f}\right) \\
& Q_{2}=h_{2} \cdot F_{2} \cdot\left(t_{m}-t_{f}\right)=h_{2} \cdot F_{2} \cdot \eta_{f} \cdot\left(t_{w}-t_{f}\right),
\end{aligned}
$$

where $Q_{1}$ and $Q_{2}$ are the quantities of heat through the first and the second surfaces, $h_{1}$ and $h_{2}$ are the heat transfer coefficients between the air and the first as well as the second heat dissipation surfaces, $F_{1}$ and $F_{2}$ are the areas of the first and the second heat dissipation surfaces, $t_{w}, t_{f}$, and $t_{m}$ are the temperatures of the tube walls, the air, and the fin surfaces. The heat distribution along the fins can not be homogeneous; thus a parameter $\eta_{f}$ is derived to represent the efficiency of the fins, as below

$$
\eta_{f}=\frac{t_{m}-t_{f}}{t_{w}-t_{f}}
$$

Based on the above, the total equivalent efficiency can be derived to describe the efficiency using only the pipe temperature $t_{w}$ and the air temperature $t_{f}$, as below

$$
\eta_{0}=\frac{F_{1}+F_{2} \cdot \eta_{f}}{F} .
$$

Omitting other derivation details, the amount of heat exchanges in a steady state is given by

$$
Q=\frac{1}{1 /\left(h_{c} \cdot F_{A} \cdot \eta_{0}\right)+1 /\left(h_{h} \cdot F_{W}\right)} \cdot \Delta t_{m}
$$

where $h_{c}$ represents the heat transfer coefficient between the cold flow and the metal surface and $h_{h}$ is the heat transfer coefficient between the hot flow and the metal surface. The thermal equilibrium equation can be written as

$$
\begin{aligned}
Q & =m_{c} \cdot c_{\mathrm{pc}} \cdot\left(t_{c 2}-t_{c 1}\right) \cdot 1000 \\
& =m_{h} \cdot c_{\mathrm{ph}} \cdot\left(t_{h 1}-t_{h 2}\right) \cdot 1000
\end{aligned}
$$

where $m_{c}$ and $m_{h}$ are the quantities of the cold and hot flows and $c_{\mathrm{pc}}$ and $c_{\mathrm{ph}}$ are constant-pressure specific heat coefficients for the cold and hot flows. Following the above calculations, 


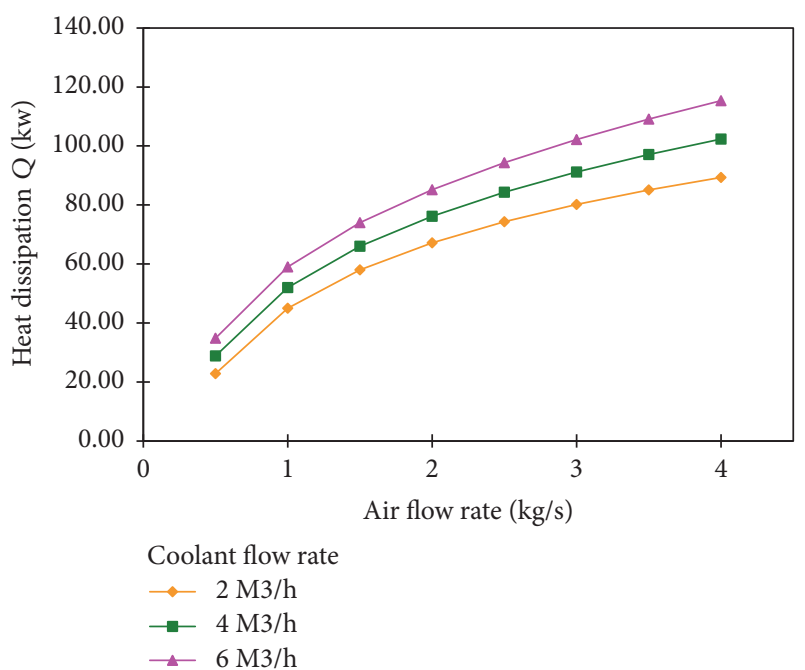

FIGURE 2: Heat dissipation ability of the radiator and fan.

the heat dissipation abilities of an existing radiator can be derived as shown in Figure 2.

Since the air flow quantity is proportional with fan speed [15], the above graph shows the nonlinear heat dissipation abilities that may be fitted by logarithm functions. Since the outlet temperature can not be adjusted again, the controller should use the inlet temperature as an input and then adjust the fan speed to achieve proper heat dissipation in the radiator, so as to get the proper temperature at the outlet from where the coolant goes into the engine. The above analysis indicates a nonlinear fan speed control strategy.

\section{Control Strategies}

The control strategies are set to use minimal fan electricity to achieve the expected temperature targets, that is, water tank outlet $85^{\circ} \mathrm{C}$, intercooler outlet $40^{\circ} \mathrm{C}$, and motor $70^{\circ} \mathrm{C}$. When a vehicle firstly starts, the engine needs to warm up to the most efficient working temperature around $60^{\circ} \mathrm{C}$; until this the water tank fan is not needed. When water tank inlet temperature is above $60^{\circ} \mathrm{C}$ the fan starts working with $30 \%$ PWM duty ratio and rises to $100 \%$ duty ratio when inlet temperature reaches $95^{\circ} \mathrm{C}$. Between $60^{\circ} \mathrm{C}$ and $95^{\circ} \mathrm{C}$, the fan speeds according to curving fitting with Figure 2 can be summarized into a logarithm function as below:

$$
\lambda_{1}=\frac{\ln (T-60)}{\ln (95-60)} .
$$

The intercooler fans start running when the inlet air temperature is above $40^{\circ} \mathrm{C}$ and the fan speed can be controlled following a similar function:

$$
\lambda_{2}=\frac{\ln (T-40)}{\ln (90-40)} .
$$

The motor fan speed is set in a linear manner when the temperature is between $50^{\circ} \mathrm{C}$ and $75^{\circ} \mathrm{C}$.

\section{Controller Hardware Design}

The control unit ECU contains two electronic boards specifically designed in the lab, one is a $+5 \mathrm{~V}$ low voltage signal processing and control board with a STC89S52 single chip microcomputer (MCU) as the core, and the other is a $+24 \mathrm{~V}$ high voltage fan drive board. The control board adopts STC89S52 MCU as the core processor for its high reliability, low costs, and well recognized reputation in many fields. As shown in Figure 3, it has a MAX813 watchdog chip to prevent the software from running out or in a dead loop and adopts an 8-bit A-D conversion chip ADC0809 to measure temperature sensors and the voltage signals were filtered in separate RC filters for each channel and then connected to ADC0809.

The outputs of the control board are five-way PWM signals, calculated by the MCU with timers and amplified through five TLP-521 optical couplers before being connected to the external motor drive board. The PWM signals generated by the control board are connected to the motor drive board, amplified separately in five channels, and then drive the fan motor. An example channel is explained in Figure 4.

The PWM signal is firstly connected to the input pin of a MIC4421 MOSFET driver chip, which has independent $15 \mathrm{~V}$ power supply that can amplify the $5 \mathrm{~V}$ PWM waves to $15 \mathrm{~V}$ PWM waves. The amplified PWM signal then goes to two large power P75NF75 MOSFET chips, parallelly connected to reduce the heat as in Figure 4. The motor current goes through the MOSFET before grounding; thus the PWM signal eventually controls the shut-off and switch-on of MOSFET and hence the motor current, which controls fan speed according to PWM theories [16-18].

Two prototypes of the ECU have been made in the lab following comprehensive schematic and PCB designs. The motor board uses LM78L15 chip to obtain the required $+15 \mathrm{~V}$ voltage for the MOSFET driver MIC4421, whilst the fan motor current directly comes from the vehicle battery and goes through the drive board via thick copper overlay and tin solder that allows up to $15 \mathrm{~A}$ current for each motor drive channel. Demonstration of the prototype is given in Figure 5.

The temperature sensors were actual products for Honda Accord Gen 7. When temperature rises, the resistance of the sensor reduces, in a nonlinear manner as shown in Figure 6. The characteristic curve was tested out by positioning the sensor in hot water and measuring resistance values. Thus, the ECU can use the fitted curve function to calculate actual temperature in water tank, and so forth.

\section{Controller Software Design}

The ECU software mainly performs the following functionalities: measure temperatures, display temperatures, decide fan speed, adjust PWM duty cycles, and output PWM signals. The PWM signals are generated in MCU using timers in a manner as shown in Figure 7.

The timer T0 is set to control the PWM substep time interval $s_{n}$. The cycle period $T c_{n}$ and hence base frequency are obtained by counting the substeps to a fixed number and inverting the signal, for example, at 10 substeps, whilst the 


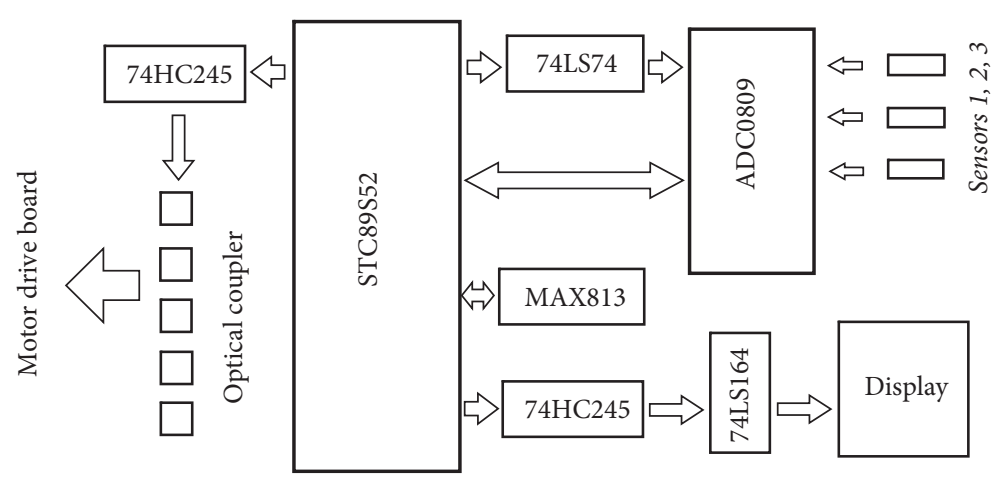

FIGURE 3: The control board sketch diagram.

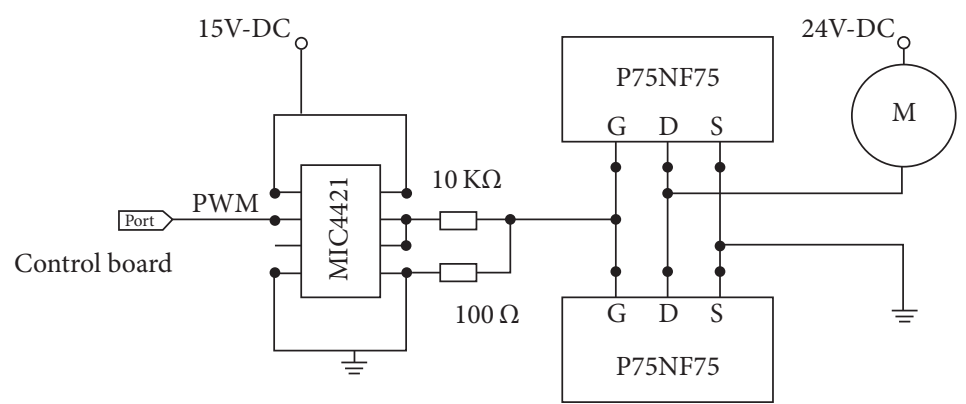

FIGURE 4: The sketch diagram of one channel of the motor drive board.

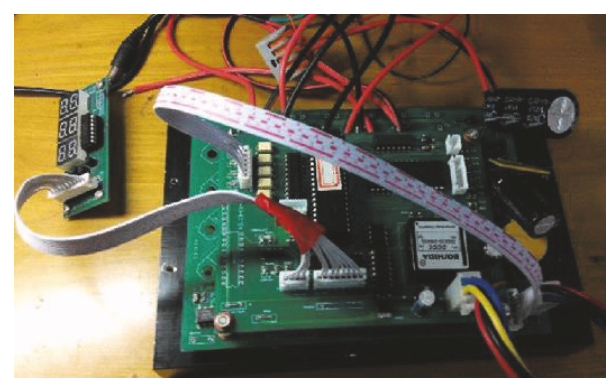

FIgURE 5: The assembled prototype of the ECU.

duty ratio is obtained by inverting the signal at a counted number within a full cycle. This approach gives more flexible control of the PWM signals comparing with some modern MCUs equipped with PWM port but difficult to amend PWM parameters within a program section.

The overall software flowchart is shown in Figure 8. When the ECU starts with the vehicle, the software firstly initializes the parameters such as timers, interrupt ports, and especially ADC0809 configurations. Since the temperature changes are slow, a large sampling gap up to $1 \mathrm{~s}$ is set in ADC0809. Then the MCU uses P1 port to control acquisition of the three signal channels and display the temperature values via serial port. When timer $T 0$ is met, the timer interrupt processing sections count the events and invert PWM signals if required. When timer $T 1$ is met, the software loops back to reread the temperature data from ADC0809. When neither of the timers is met, the software keeps refreshing the display unit.
A watchdog control signal is sent to the MAX813 chip to ensure the software is in healthy running. When the watchdog chip detects error the software restarts the MCU.

\section{Experiments}

Experiments were carried out in the lab to verify fan control performance and on a vehicle to verify actual usability and optimal control strategies.

6.1. Bench Tests. The bench tests in the lab as demonstrated in Figure 9 were carried out to evaluate sensor sensitivity, PWM fan drive effectiveness, and durability. A major issue that has arisen was due to the frequency of PWM signals, which according to literatures [16-18] may lead to noises, vibration, or even damage to the motor if the frequency is not properly configured and falls in resonance with the mechanical parts.

The PWM frequency effects can be seen in the test results in Table 1. As literature suggested [17], the proper PWM base frequency should be either as high as $10 \mathrm{~K}-20 \mathrm{~K} \mathrm{~Hz}$ or as low as $50-200 \mathrm{~Hz}$ to minimize noises and vibration, whilst the $1 \mathrm{~K}-2 \mathrm{~K} \mathrm{~Hz}$ frequency is the worst range. For the above reasons, the final PWM base frequency was chosen to be $100 \mathrm{~Hz}$ and small duty ratios less than $30 \%$ were avoided, so that the fans could stop directly when the calculated duty ratio reduces to $30 \%$.

6.2. On-Vehicle Tests. On-vehicle tests were carried out on a LCK6118P hybrid electrical bus provided by Zhongtong Bus Holding Co., Ltd., in Liaocheng city, China. The actual configuration of the fans and the working environment is 



Figure 6: The temperature sensor and electrical characteristic.

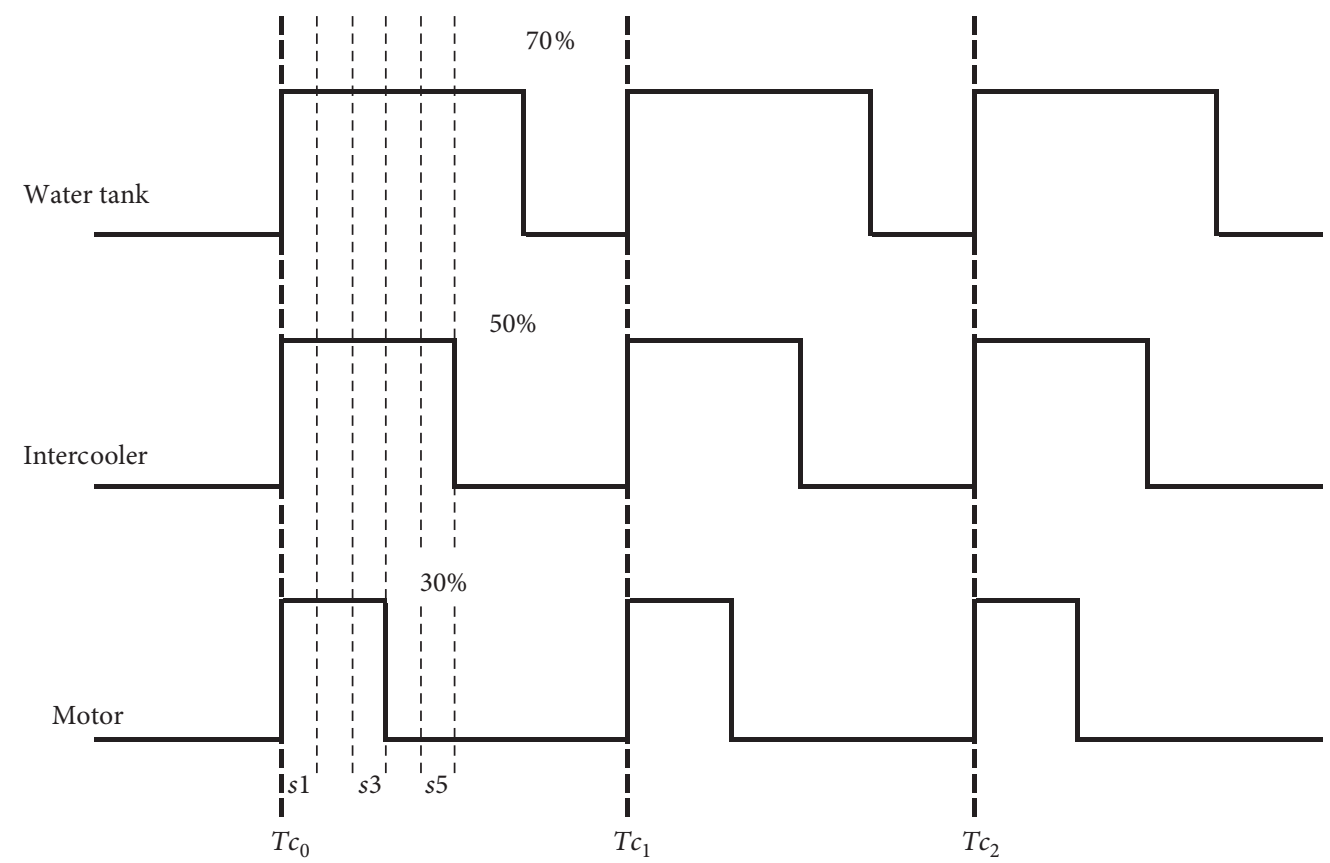

FIGURE 7: The sketch diagram of the generated PWM signals.

shown in Figure 10. Temperature values and fan speeds were read from the ECU and recorded for analysis, and extra temperature sensors were also added at the outlet of the water tank to analyze the changes and effectiveness.

The equipment specifications are provided in Table 2. The tests were carried out in the vehicle test yard within Zhongtong Bus Holding Co., Ltd., using different speed settings for varying durations, with specified numbers of starts and stops.

The tests are still undergoing and more experiments would be carried out along bus routes in the city. So far initial results indicate some sensible relationships between fan speeds and the reduction of coolant temperatures measured at the inlet and outlet of the radiator. From the recorded data in the ECU, temperature and fan speed data pairs were selected and plotted in Figure 11. When the inlet coolant temperatures are $95^{\circ}$ and $90^{\circ}$, respectively, the temperature reduction measured at the outlet changes with fan speed in a nonlinear manner, which is consistent with the theoretically predicted trends in Figure 2.

For the intercooler, the fluid inside the radiator is turbo pressurized air, which is compressed in the turbo and cooled in the intercooler and then fed into the diesel engine to boost the engine power. The temperature reductions with fan speeds are shown in Figure 12. The motor mainly drives the vehicle in high torque stop-start short periods and therefore it is not tested in the current study.

Comparing with old fashion on-off control system that always uses $100 \%$ fan speed, the above strategies would significantly reduce power consumption. The cooling fans totally cost $1.5 \mathrm{KW}$ electricity when they are fully running, which counts $62.5 \%$ of a typical $100 \mathrm{AH}$ battery. Although a battery can be recharged after starting, the main drive motor consumes the majority of the electricity. According to 


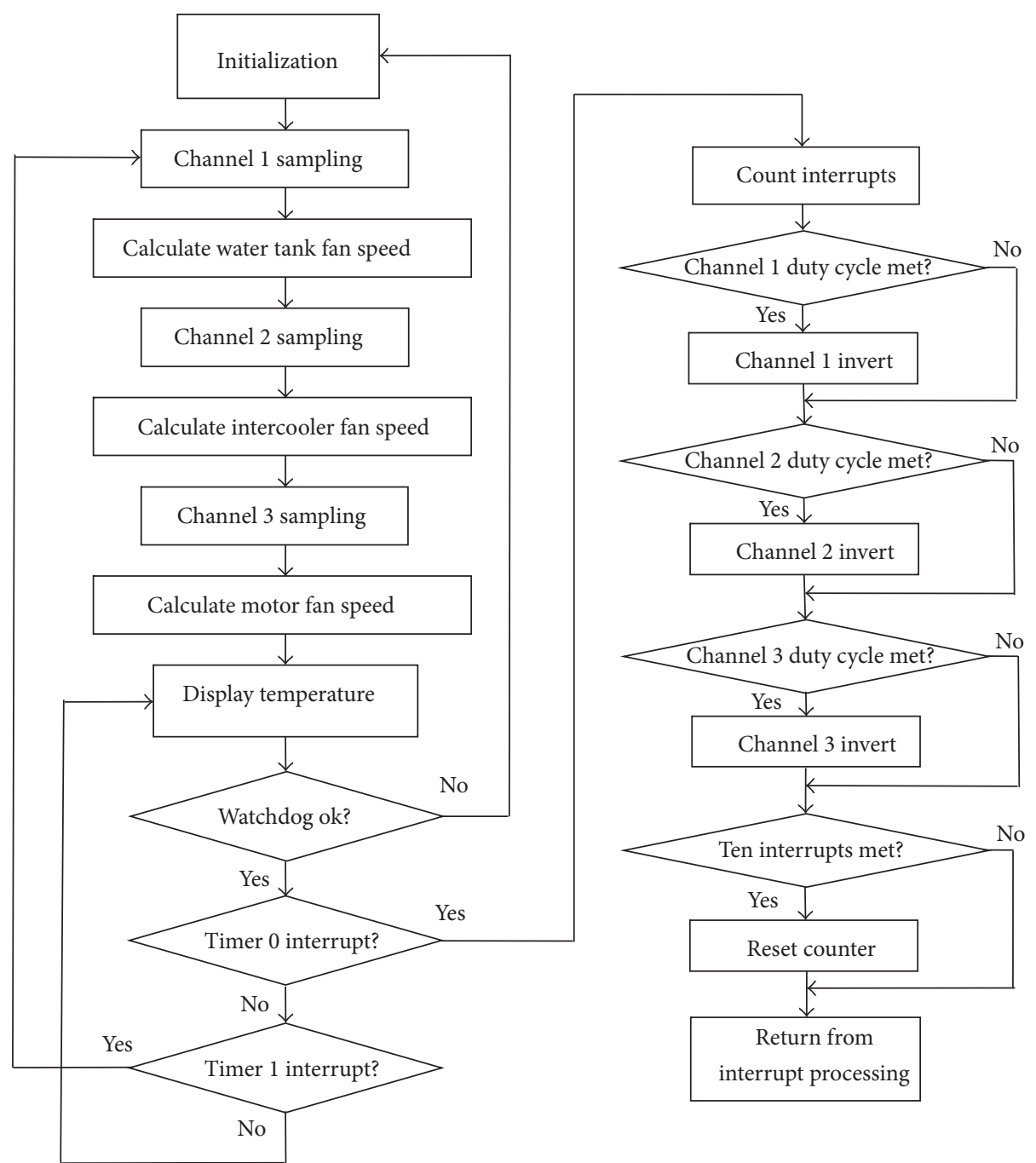

FIgURE 8: The flow chart of the ECU control software.

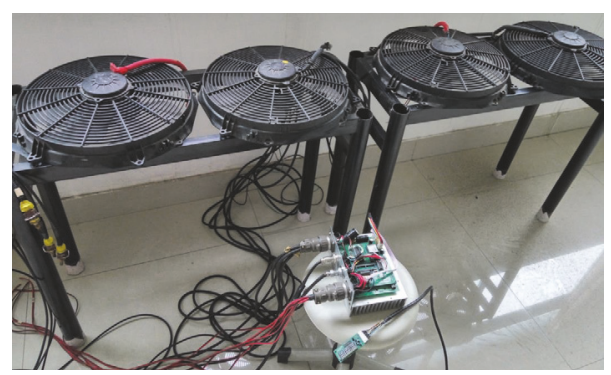

FIGURE 9: In lab bench test of the ECU control system.

Figure 11 it can be seen that, in order to control radiator outlet temperature to be no more than $85^{\circ} \mathrm{C}$, then the fan speed should be set to $100 \%$ if the inlet temperature is $95^{\circ} \mathrm{C}$, and only use $60 \%$ speed if the inlet temperature is $90^{\circ} \mathrm{C}$.

According to China's national standard GBT 18386-2005, typical vehicle tests on city road can be simulated by a number of identical test cycles and each cycle is described in Figure 13. Within such cycle, it can be assumed that the acceleration pedal is released during the speed reduction periods and zero-speed periods. Experiments indicated that the radiator inlet temperature can well drop from $95^{\circ} \mathrm{C}$ to $90^{\circ} \mathrm{C} 10$ seconds after the acceleration pedal is released. Thus, there is together 22 seconds out of the total 200 seconds that only needs $60 \%$ fan speed. Taking into account the temperature changing periods, it is reasonable to assume that the cooling system can save at least $15 \%$ of the total electrical energy. 

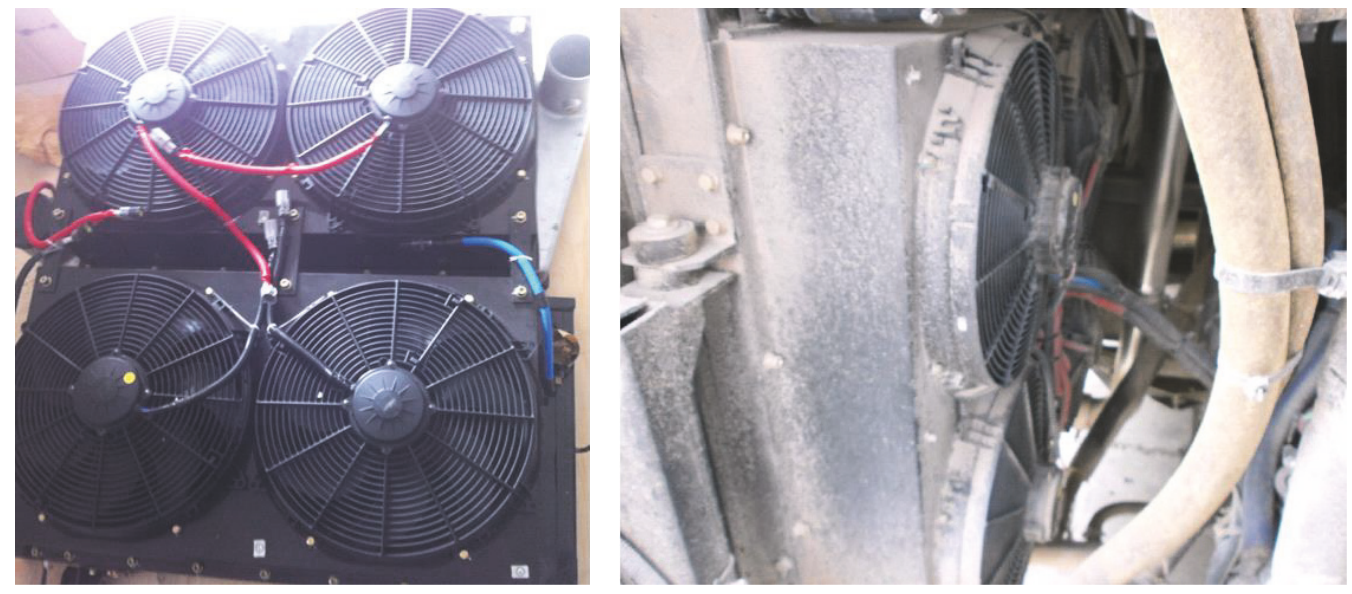

FIgURE 10: Actual fan and on-vehicle configurations for driving test.

TABLE 1: PWM frequency and fan speed test results.

\begin{tabular}{lccc}
\hline Base frequency $(\mathrm{Hz})$ & Duty ratio (\%) & Performance & Durability \\
\hline 100 & 10 & Noisy & Not tested \\
100 & 20 & Slightly noisy & Not tested \\
100 & 30 & Quiet \& smooth & Above 24 hours \\
100 & 50 & Quiet \& smooth & Above 24 hours \\
100 & 90 & Quiet \& smooth & Above 24 hours \\
1000 & 30 & Very noisy & Not tested \\
1000 & 90 & Noisy & Not tested \\
10000 & 30 & Slightly noisy & Not tested \\
10000 & 90 & Quiet \& smooth & 24 hours with reboots \\
\hline
\end{tabular}

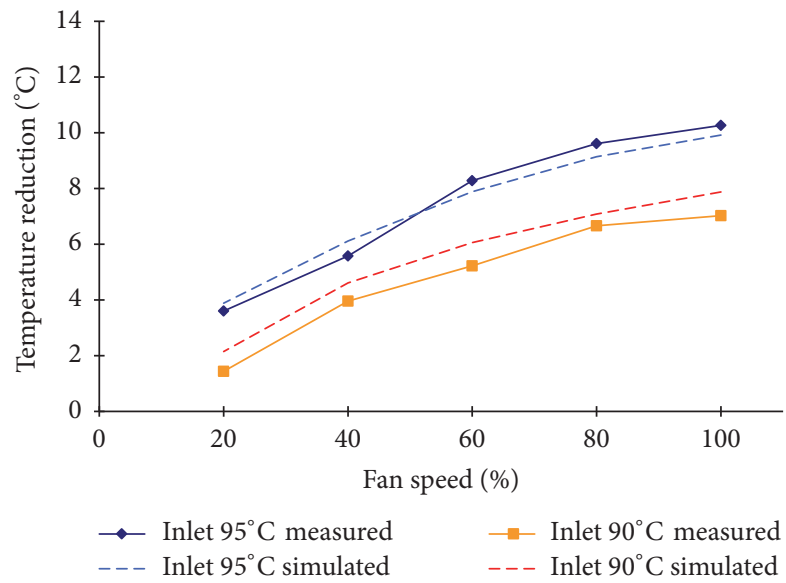

Figure 11: Test results for water tank fan speed and temperature reduction.

\section{Conclusion}

This study presents a design of an integrated cooling system controller ECU for hybrid electrical vehicle. Temperatures in the water tank, intercooler, and main drive motor are measured by the MCU to control optimal fan speeds. The ECU also consists of a five-way large power fan motor drive

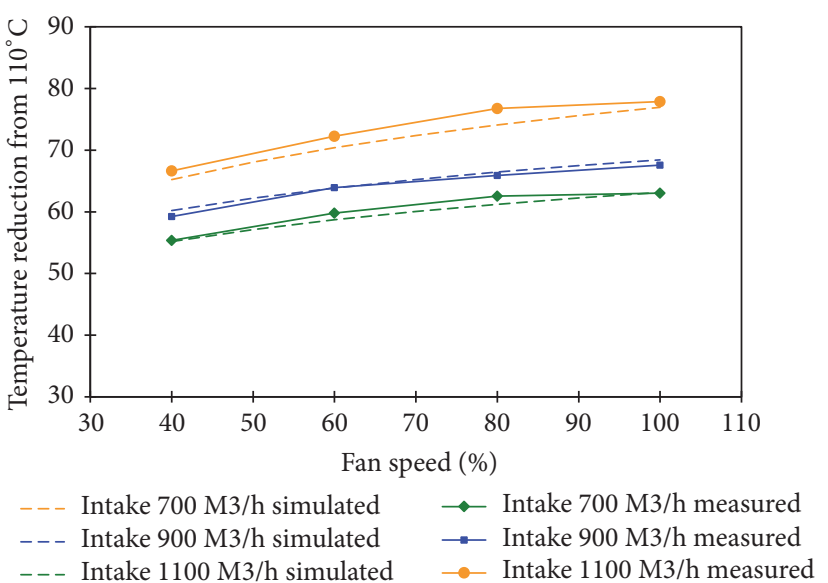

FIGURE 12: Test results for intercooler fan speed and temperature reduction.

board to perform PWM fan speed control. Comprehensive experiments have been carried out to verify the ECU performance and to identify optimal fan speed control strategies. The PWM fan drive frequency has been determined in bench tests and the speed adjustment strategies were firstly analyzed using theories and then compared with experimental data. The ECU design is robust and it can save at least $15 \%$ of the 


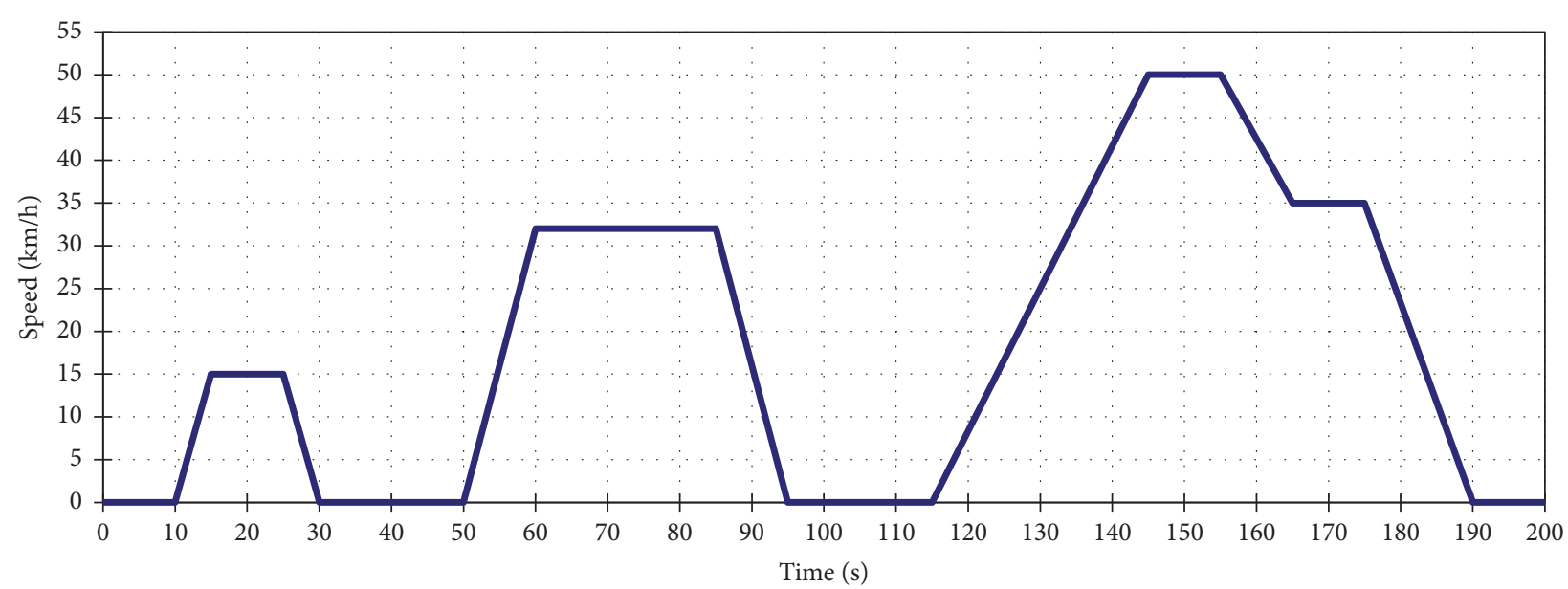

FIGURE 13: A typical city test cycle according to GBT 18386-2005.

TABLE 2: Specifications of the equipment for experiments.

\begin{tabular}{lc}
\hline Equipment & Specification \\
\hline Engine model & YC6L280-42 \\
Engine type & Turbo Diesel \\
Rated power/speed & $206 \mathrm{KW} / 2200 \mathrm{r} / \mathrm{min}$ \\
Max. torque/speed & $1100 \mathrm{~N} \cdot \mathrm{m} \leq 1500 \mathrm{r} / \mathrm{min}$ \\
Rated coolant temperature & $\leq 95^{\circ} \mathrm{C}$ \\
Water pump flow rate & $\leq 420 \mathrm{~L} / \mathrm{min}$ \\
Heat with rated power & $\mathrm{Qw}=117 \mathrm{Kw}$ \\
Heat with rated torque & Qw $=82.5 \mathrm{Kw}$ \\
Fan diameter & $385 \mathrm{~mm}$ \\
Fan electrical power & $300 \mathrm{~W}$ \\
Radiator total area & $48.76 \mathrm{~m}^{2}$ \\
Radiator front area & $0.5724 \mathrm{~m}{ }^{2}$ \\
Radiator dissipation power & $150 \mathrm{KW}$ \\
Radiator wave length & $4.2 \mathrm{~mm}$ \\
Radiator wave height & $10 \mathrm{~mm}$ \\
Radiator number of pipes & 135 \\
Radiator number of ribbons & 46 \\
Radiator pipe size & $13 \times 2(\mathrm{~mm})$ \\
Intercooler total area & $20.87 \mathrm{~m}^{2}$ \\
Intercooler front area & $0.3465 \mathrm{~m}{ }^{2}$ \\
Intercooler dissipation power & $50 \mathrm{KW}$ \\
Intercooler wave length & $3.5 \mathrm{~mm}$ \\
Intercooler wave height & $8 \mathrm{~mm}$ \\
Intercooler number of pipes & 74 \\
Intercooler number of ribbons & 38 \\
Intercooler pipe size & $13 \times 2(\mathrm{~mm})$ \\
\hline &
\end{tabular}

total electricity on normal city routes. Further work should be expanded to take into account extra influential factors such as vehicle speed, environmental temperature and make use of CAN bus data to create a more advanced controller.

\section{Conflicts of Interest}

The authors declare that they have no conflicts of interest.

\section{Acknowledgments}

This study is supported by Liaocheng University Research Fund 13LD2001.

\section{References}

[1] K. Reif, Automotive Mechatronics: Automotive Networking, Driving Stability Systems, Electronics, Springer, 2015.

[2] S. Park, A comprehensive thermal management system model for hybrid electric vehicles [Ph.D. thesis], University of Michigan, Ann Arbor, Mich, USA, 2011.

[3] C. Alaoui and Z. M. Salameh, "A novel thermal management for electric and hybrid vehicles," IEEE Transactions on Vehicular Technology, vol. 54, no. 2, pp. 468-476, 2005.

[4] Y.-H. Hung, Y.-X. Lin, C.-H. Wu, and S.-Y. Chen, "Mechatronics design and experimental verification of an electricvehicle-based hybrid thermal management system," Advances in Mechanical Engineering, vol. 8, no. 2, pp. 1-9, 2016.

[5] K. J. Kelly, T. Abraham, K. Bennion, D. Bharathan, S. Narumanchi, and M. O'Keefe, "Assessment of thermal control technologies for cooling electric vehicle power electronics," in Proceedings of the 23rd International Electric Vehicle Symposium, Anaheim, Calif, USA, 2007.

[6] H. H. Pang and C. J. Brace, "Review of engine cooling technologies for modern engines," Proceedings of the Institution of Mechanical Engineers Part D: Journal of Automobile Engineering, vol. 218, no. 11, pp. 1209-1215, 2004.

[7] S. S. Butt, R. Prabel, and H. Aschemann, "Robust inputoutput linearization with input constraints for an engine cooling system," in Proceedings of the American Control Conference (ACC '14), pp. 4555-4560, IEEE, June 2014.

[8] M. H. Salah, T. H. Mitchell, J. R. Wagner, and D. M. Dawson, "Nonlinear-control strategy for advanced vehicle thermalmanagement systems," IEEE Transactions on Vehicular Technology, vol. 57, no. 1, pp. 127-137, 2008.

[9] P. Setlur, J. R. Wagner, D. M. Dawson, and E. Marotta, "An advanced engine thermal management system: nonlinear control and test," IEEE/ASME Transactions on Mechatronics, vol. 10, no. 2, pp. 210-220, 2005.

[10] W. Lothar Seybold, F. Filsinger, B. Gruber, I. Taxis, and A. Lazaridis, "Optimization of an engine coolant radiator for 
vehicle thermal management," in Proceedings of the 16th Internationales Stuttgarter Symposium Part of the series Proceedings, pp. 1465-1482, 2016.

[11] J.-X. Liu, S.-C. Qin, Z.-Y. Xu, A. Zhang, Y. Xi, and X.-L. Zhang, "Comparative analysis of heat exchange performance of vehicle radiator based on CFD numerical simulation," Journal of South China University of Technology, vol. 40, no. 5, pp. 24-29, 2012.

[12] C. Park and A. K. Jaura, "Thermal analysis of cooling system in hybrid electric vehicles," Tech. Rep. SAE 2000-01-0710, 2002.

[13] W. Zhu, Z. Tian, and Y. Zhang, "Prediction model of heat transfer and resistance of pipe belt type automobile radiator," Modern Business Trade Industry, vol. 5, pp. 186-188, 2012.

[14] H. Fei, J. Tian, S. Lei, Y. Chen, and W. Yan, "CFD analysis of the thermal management system of the engine room of the passenger car," Internal Combustion Engine \& Power Plant, vol. 1, pp. 25-28, 2014.

[15] T. Ismael, S. B. Yun, and F. Ulugbek, "Radiator heat dissipation performance," Journal of Electronics Cooling and Thermal Control, vol. 6, no. 2, pp. 88-96, 2016.

[16] S. Shrivastava, J. Rawat, and A. Agrawal, "Controlling DC motor using microcontroller (PIC16F72) with PWM," International Journal of Engineering Research, vol. 1, no. 2, pp. 45-47, 2012.

[17] J. M. Najm Abad, B. Salami, H. Noori, A. Soleimani, and F. Mehdipour, "A neuro-fuzzy fan speed controller for dynamic thermal management of multi-core processors," in Proceedings of the 11th ACM Conference on Computing Frontiers, article no. 29, ACM, New York, NY, USA, 2014.

[18] V. Bhatia and G. Bhatia, "Room temperature based fan speed control system using pulse width modulation technique," International Journal of Computer Applications, vol. 81, no. 5, pp. 3540, 2013. 


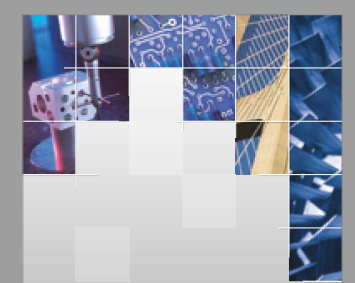

\section{Enfincering}
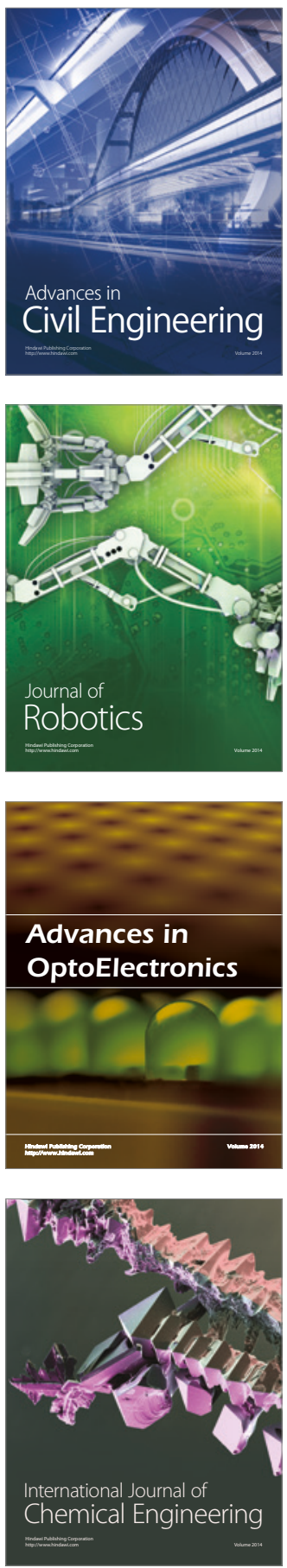

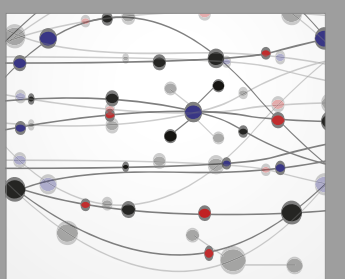

The Scientific World Journal

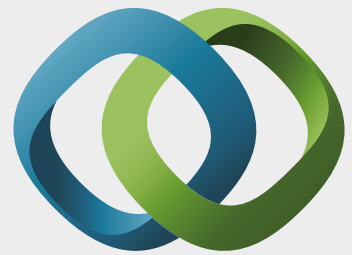

\section{Hindawi}

Submit your manuscripts at

https://www.hindawi.com
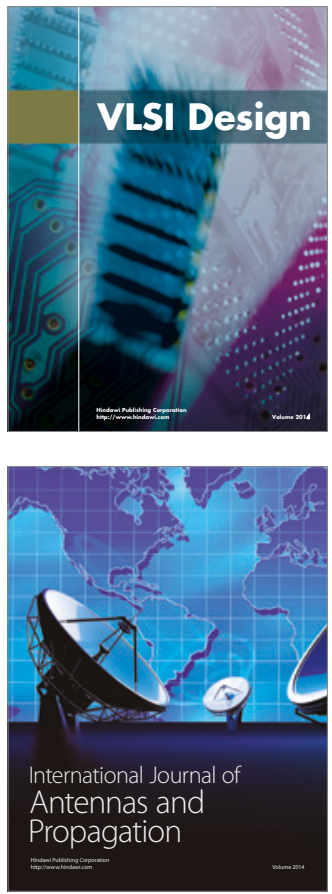

\section{Rotating}

Machinery
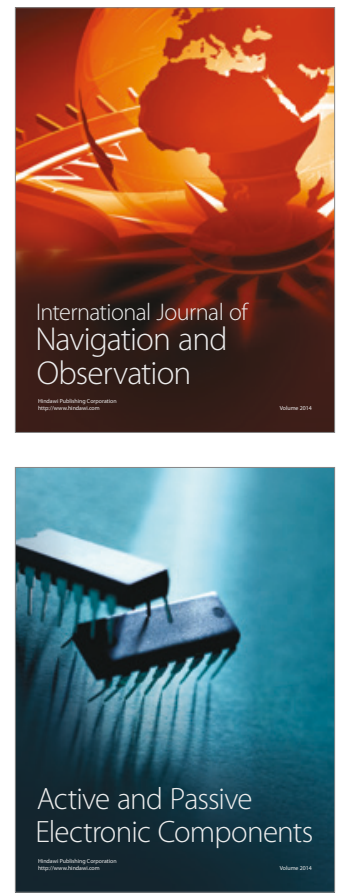
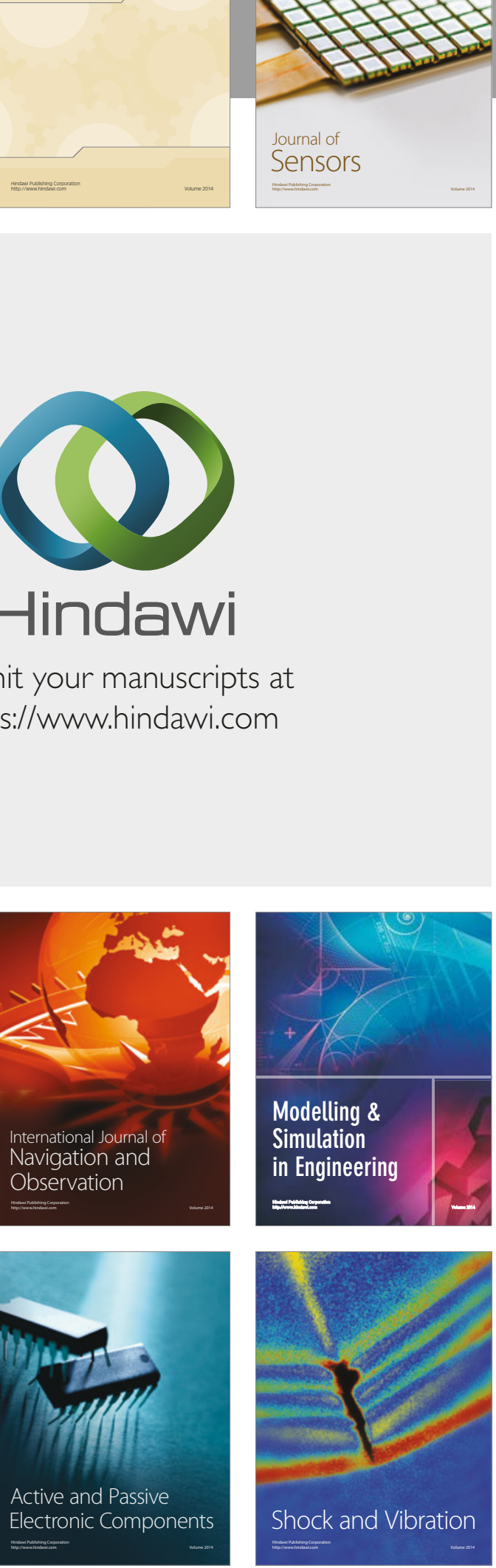
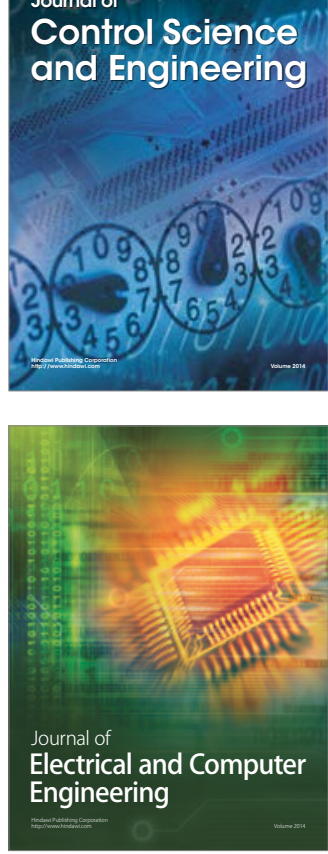

Distributed

Journal of

Control Science

and Engineering
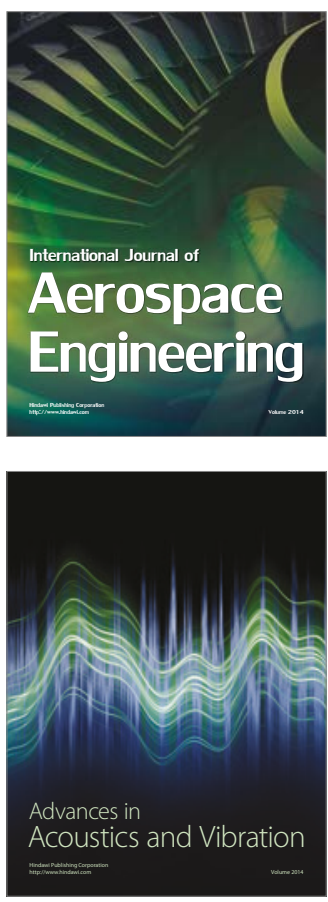

Sensor Networks 